NBER WORKING PAPER SERIES

\title{
ENFORCEMENT PROBLEMS AND SECONDARY MARKETS
}

\author{
Fernando A. Broner \\ Alberto Martin \\ Jaume Ventura \\ Working Paper 13559 \\ http://www.nber.org/papers/w13559
NATIONAL BUREAU OF ECONOMIC RESEARCH
1050 Massachusetts Avenue
Cambridge, MA 02138
October 2007

The views expressed herein are those of the author(s) and do not necessarily reflect the views of the National Bureau of Economic Research.

(C) 2007 by Fernando A. Broner, Alberto Martin, and Jaume Ventura. All rights reserved. Short sections of text, not to exceed two paragraphs, may be quoted without explicit permission provided that full credit, including $(\mathrm{C}$ notice, is given to the source. 
Enforcement Problems and Secondary Markets

Fernando A. Broner, Alberto Martin, and Jaume Ventura

NBER Working Paper No. 13559

October 2007

JEL No. F34,F36,G15

\begin{abstract}
$\underline{\text { ABSTRACT }}$
There is a large and growing literature that studies the effects of weak enforcement institutions on economic performance. This literature has focused almost exclusively on primary markets, in which assets are issued and traded to improve the allocation of investment and consumption. The general conclusion is that weak enforcement institutions impair the workings of these markets, giving rise to various inefficiencies. But weak enforcement institutions also create incentives to develop secondary markets, in which the assets issued in primary markets are retraded. This paper shows that trading in secondary markets counteracts the effects of weak enforcement institutions and, in the absence of further frictions, restores efficiency.
\end{abstract}

\author{
Fernando A. Broner \\ CREI - Universitat Pompeu Fabra \\ Ramon Trias Fargas, 25-27 \\ 08005 Barcelona \\ Spain \\ fbroner@crei.cat \\ Alberto Martin \\ CREI - Universitat Pompeu Fabra \\ Ramon Trias Fargas, 25-27 \\ 08005 Barcelona \\ Spain \\ alberto.martin@upf.edu
}

\author{
Jaume Ventura \\ CREI - Universitat Pompeu Fabra \\ Ramon Trias Fargas, 25-27 \\ 08005-Barcelona \\ Spain \\ and NBER \\ jaume.ventura@upf.edu
}




\section{Introduction}

Markets cannot exist without an adequate institutional framework that ensures that asset payments are enforced. Most market transactions involve the exchange of explicit or implicit promises of a future delivery of goods. More often than not, there is a date in which the first party of the transaction has already complied with his obligations but is still waiting for the second party to do so. At this point, the first party cannot trust the good will of the second party but must instead rely on public or private enforcement institutions to do their job and force the second party to comply with her obligations too. Otherwise, the first party would not have purchased the asset in the first place and the transaction would never have happened. The logic of this argument is compelling and has been known for a long time. And yet it is only recently that economists have started to pay serious attention to the effects of weak institutions and developed a large and growing literature that deals with this topic. ${ }^{1}$

This literature seems to have overlooked though some important effects that weak institutions have on markets. In particular, the focus of existing research has been almost exclusively on how weak institutions impair the workings of primary markets where assets are issued and traded to improve the allocation of investment and consumption. But weak institutions also create incentives to develop secondary markets where the assets issued in primary markets are retraded so as to solve enforcement problems. For instance, in Broner, Martin and Ventura (2006), we showed how secondary markets can support the optimal amount of foreign trade even in situations in which the problem of sovereign risk is so severe that no foreign trade would be possible in their absence.

The goal of this short paper is to further explore the role of secondary markets in solving enforcement problems. Given the tight space constraints, we cannot provide a full treatment of the issues. Instead, we work with a simple setup that helps connect all the ideas minimizing notation and formalities. This setup is the Debtor world, and it is as follows:

Definition 1 (The Debtor world). The Debtor world lasts two periods, Today and Tomorrow, indexed by $t \in\{0,1\}$; and contains a region named Debtor and an international financial market. There is a continuum with mass one of debtors (i.e. residents of Debtor), indexed by $i \in I$, that maximize $U\left(c_{i 0}, c_{i 1}\right)=u\left(c_{i 0}\right)+E_{0}\left[u\left(c_{i 1}\right)\right]$; where $c_{i t}$ is the consumption of debtor $i$ in period $t$, $u^{\prime}(\cdot)>0$ and $u^{\prime \prime}(\cdot) \leq 0$. Today, debtors receive an endowment of $0.5 \cdot y$. Tomorrow, half of them are lucky and receive an endowment of $2 \cdot y$, while the rest are unlucky and receive an endowment of y. Today, all debtors are equally likely to be lucky or unlucky. The international financial market acts competitively, is risk neutral, does not discount the future, has deep pockets, can commit to

\footnotetext{
${ }^{1}$ See Dixit (2006) for a short introduction.
} 
make payments Tomorrow, and is therefore able and willing to buy or sell any asset offering zero expected return.

In the Debtor world, debtors want to go to the international financial market to insure against endowment risk Tomorrow and also to borrow and increase consumption Today. Without enforcement problems, the price of a state-contingent bond that pays one unit of consumption Tomorrow when debtor $i$ is lucky (henceforth an " $i$-lucky" bond) would be 0.5 since this is the probability that this debtor be lucky. Similarly, the price of a state-contingent bond that pays one unit of consumption Tomorrow when debtor $i$ is unlucky (henceforth an " $i$-unlucky" bond) would also be 0.5. These prices are independent of who issues these bonds, which could be debtor $i$ himself or somebody else. ${ }^{2}$ Taking this into account, debtor $i$ 's budget set can be written as follows:

$$
c_{i 0}=0.5 \cdot\left(y-x_{i 0}^{L_{i}}-x_{i 0}^{U_{i}}\right) \quad \text { and } \quad c_{i 1}= \begin{cases}2 \cdot y+x_{i 0}^{L_{i}} & \text { if lucky } \\ y+x_{i 0}^{U_{i}} & \text { if unlucky }\end{cases}
$$

where $x_{i 0}^{L_{i}}$ and $x_{i 0}^{U_{i}}$ stand for the debtor $i$ 's holdings of $i$-lucky and $i$-unlucky bonds, respectively. ${ }^{3}$ The first-order conditions of debtor $i$ 's maximization problem are:

$$
u^{\prime}\left(c_{i 0}\right)=u^{\prime}\left(c_{i 1} \mid \text { lucky }\right)=u^{\prime}\left(c_{i 1} \mid \text { unlucky }\right)
$$

The budget set and the first-order conditions jointly determine consumptions and the trades that support them. Debtors choose to smooth consumption, i.e. $c_{i 0}=c_{i 1}=y$; and to implement this consumption plan they borrow $0.5 \cdot y$ Today and promise to pay $y$ Tomorrow if they are lucky, i.e. $x_{i 0}^{L_{i}}=-y$ and $x_{i 0}^{U_{i}}=0$.

The problem, of course, is that Tomorrow lucky debtors will prefer not to make payments to the international financial market. The question we address here is whether Debtor's government will enforce these payments and what role, if any, secondary markets play in solving enforcement problems. ${ }^{4}$ In Section 2, we consider a situation in which Debtor's government acts opportunistically and is unwilling to enforce payments to the international financial market. This is the classic problem of sovereign risk that we analyzed in Broner, Martin and Ventura (2006). In Section 3, we consider instead a situation in which Debtor's court system is imperfect and might be unable to

\footnotetext{
${ }^{2}$ Throughout, we assume that enforcement of asset payments involving a debtor are always decided by Debtor's government. This assumption streamlines the presentation since it ensures that bonds issued by debtors and the international financial markets are perfect substitutes. None of the results of this paper depends on this assumption.

${ }^{3}$ Naturally, this debtor could choose from a much larger set of assets. But it would not be able to improve upon what he/she can already do with these two state-contingent bonds.

${ }^{4}$ We assume that the only enforcement institutions are public. See Dixit (2007) for a wide-ranging discussion of private enforcement institutions.
} 
enforce all payments. The analysis of this problem of weak law enforcement is new to this paper. We show how, in each case, secondary markets solve the relevant enforcement problem allowing debtors to smooth their consumption.

Trading in secondary markets plays different roles in these examples however. While in the sovereign-risk example this trading provides incentives to the government to enforce payments, in the weak-law-enforcement example this trading insures individuals against unavoidable enforcement errors. In Section 3, we also show that these roles are compatible and secondary markets can cope with both types of enforcement problems simultaneously. We conclude in Section 4 with a discussion of when and why secondary markets might fail to solve enforcement problems.

\section{Unwillingness to enforce and secondary markets}

Sovereign risk arises if countries act strategically or opportunistically when deciding whether to enforce debt payments to foreigners, thus creating the possibility of default. There is a longstanding tradition of thinking about this problem as being one of insufficient collateral or penalties. ${ }^{5}$ If this insufficiency is known ex-ante, sovereign risk constraints credit as foreigners understand that countries will not repay their foreign debts if they exceed the value of penalties and collateral. If this insufficiency is partly discovered ex-post, sovereign risk leads countries to default when the value of penalties and collateral falls short of their foreign debts. Both credit constraints and defaults generate inefficiencies that lower welfare. According to this traditional view, the "cure" for sovereign risk is to create enough collateral and penalties.

In Broner, Martin and Ventura (2006), we proposed an alternative (but complementary) view of the problem of sovereign risk as one of missing markets. Implicitly or explicitly, the previous literature has assumed that secondary markets are missing. But this assumption turns out to be crucial since, even if the amount of collateral and penalties is arbitrarily small, foreign creditors can always go to secondary markets to sell their debts and circumvent the strategic or opportunistic behavior of governments. According to this alternative view, sovereign risk is only a problem if secondary markets do not work well and its cure simply consists of improving them. We briefly review this argument next within the context of our simple Debtor world.

Assume that Debtor's government chooses enforcement to maximize the average utility of debtors. This can be achieved by committing Today to enforce all payments Tomorrow. The

\footnotetext{
${ }^{5} \mathrm{By}$ collateral we refer to the value of the real assets that foreign creditors can directly seize in the event of default. By penalties we refer to the value of the payments that foreign creditors can elicit in the event of deafult through the threat of applying penalties of various sorts, including trade embargoes and losses of reputation. Conceptually, collateral and penalties play the same role in the theory and therefore makes sense to treat them jointly.
} 
problem is that Debtor's government lacks credibility and any promise it makes Today is rightly discounted by market participants. Assume further that Debtor cannot offer collateral and the international financial market cannot impose penalties. Conventional wisdom suggests that in this situation only domestic trade is possible. The reason for this seems straightforward: once Tomorrow arrives, Debtor's government will never enforce payments from debtors to the international financial market. Doing so would reduce the consumption of debtors and, due to the lack of collateral and penalties, it would not provide any benefits in return. Anticipating default Tomorrow, the international financial market does not lend to debtors Today. ${ }^{6}$

The main result in our previous paper is that this apparently flawless logic hinges on the implicit assumption that there are no secondary markets. In conventional models, individuals trade Today in primary markets but cannot trade again Tomorrow in secondary markets before enforcement takes place. And yet we showed that if we opened these secondary markets, individuals would actively trade in them with the unexpected consequence of eliminating the problem of sovereign risk.

To see this, assume that the international financial market ignores sovereign risk and purchases from each debtor $i$ an amount $y$ of $i$-lucky bonds at price 0.5 in primary markets. Would this be rational behavior given that Debtor's government acts opportunistically and there is neither collateral nor penalties? The answer is positive if the secondary market works well. Since Debtor's government will never enforce payments from debtors to the international financial market, the latter will be willing to sell all $i$-lucky bonds at any positive price. If Debtor's government enforces payments between debtors, these will be willing to buy $i$-lucky bonds at face value. ${ }^{7}$ In equilibrium, all debts will be repaid. Naturally, we have derived this result under the assumption that Debtor's government enforces payments between debtors. But it is easy to see that this is actually not an assumption, but an equilibrium outcome. After the secondary market closes, all bonds are in the hands of debtors and default can only redistribute consumption among them increasing inequality and lowering average utility. Therefore, the government prefers to enforce payments between debtors.

It is worth introducing a bit of notation to expand on this last point. Let $x_{i 1}^{L}$ be debtor $i$ 's net holdings of bonds issued by lucky debtors after trading in the secondary market. If the government enforces, all debtors consume $y$. If the government does not enforce, debtor $i$ consumes $y$ minus $x_{i 1}^{L}$. Debtor's government enforces if the average utility under enforcement is equal or greater than

\footnotetext{
${ }^{6}$ This would not prevent domestic residents from insuring each other though. Insurance payments are made by lucky debtors and received by unlucky. Since the former have lower marginal utility of consumption than the latter, these payments raise average utility and would be enforced by the government. Without secondary markets, all debtors would consume $0.5 \cdot y$ Today and $1.5 \cdot y$ Tomorrow regardless of whether they are lucky or unlucky.

${ }^{7}$ If debtor $i$ is unlucky, the face value of an $i$-lucky bond is zero.
} 
under non-enforcement, that is: ${ }^{8}$

$$
u(y) \geq \int_{i \in I} u\left(y-x_{i 1}^{L}\right)
$$

Since all outstanding bonds are bought back in the secondary market, i.e. $\int_{i \in I} x_{i 1}^{L}=0$, and preferences are concave, i.e. $u^{\prime \prime}(\cdot) \leq 0$, this inequality must hold in equilibrium. Therefore, any distribution of bond holdings that satisfies $\int_{i \in I} x_{i 1}^{L}=0$ equates demand and supply in the secondary market and ensures that all debt payments are enforced.

The key insight of this example is that secondary markets allow market participants to protect themselves against the unwillingness of governments to enforce payments. By transferring assets from those that are less liked by Debtor's government (the international financial market) to those that are more liked (debtors) secondary markets maximize the cost of default and lead the government to enforce all bonds. The optimal consumption plan can therefore be implemented. ${ }^{9}$ To prove this result we have assumed that Debtor's government can costlessly enforce payments if it is willing to do so. Would secondary markets also be able to solve a situation in which Debtor's government does not have this ability? We turn to this question next.

\section{$3 \quad$ Inability to enforce and secondary markets}

Many enforcement problems do not stem from governments' unwillingness to enforce payments but instead from their inability to do so. As Avinash Dixit explains:

"In all countries through much of their history, the apparatus of state law was very costly, slow, unreliable, biased, corrupt, weak, or simply absent. In most countries this situation still prevails. Markets with such weak underpinnings of law differ greatly from those depicted in conventional economic theory." Dixit (2004, p.3)

We entirely agree with Dixit's diagnosis of the problem. The last sentence is ambiguous, though, and lends itself to two alternative interpretations. Both take as the reference point countries with strong law enforcement where markets play the role of allocating investments and consumption efficiently. The first interpretation, (and surely the one that Dixit had in mind) is that weak law enforcement impairs the workings of primary markets leading to an inefficient allocation of

\footnotetext{
${ }^{8}$ This condition is valid under the assumption that Debtor's government cannot discriminate among debtors when choosing enforcement policy. This assumption simplifies the exposition but is not crucial for the argument. See Broner, Martin and Ventura (2006).

${ }^{9}$ How robust is the result that secondary markets solve the problem of unwillingness to enforce? In our previous paper, we showed that it does not depend on the particular form of the government's objective function and it extends to environments with many regions, many periods, many shocks, most exogenous types of market incompleteness, and many sources of heterogeneity within and between regions.
} 
investment and consumption. The second interpretation (and the one we shall emphasize here) is that weak law enforcement provides incentives for the creation of secondary markets with the alternative role of solving enforcement problems.

We return to our familiar Debtor world to make this point. To emphasize the difference between unwillingness and inability to enforce, we assume now that Debtor's government can credibly commit Today to try to enforce payments Tomorrow. This eliminates the problem of sovereign risk discussed in Section 2. However, enforcement is carried out by courts and these work imperfectly.

\subsection{Enforcement breakdown}

Assume next that there is a probability $\delta \in[0,1)$ that the court system collapses and no asset payments are enforced. Although extreme, this example is useful because it clearly illustrates the effects of secondary markets when governments are unable to enforce.

Consider first the usual case in which, for unspecified reasons, secondary markets are missing. Given our assumptions about the international financial market, the price of $i$-lucky ( $i$-unlucky) bonds must be $0.5 \cdot(1-\delta)$ since this is the probability that both debtor $i$ be lucky (unlucky) and there be no enforcement breakdown. ${ }^{10}$ Therefore, the budget set of debtor $i$ can be written now as follows:

$$
c_{i 0}=0.5 \cdot\left(y-(1-\delta) \cdot\left(x_{i 0}^{L_{i}}+x_{i 0}^{U_{i}}\right)\right) \quad \text { and } \quad c_{i 1}= \begin{cases}2 \cdot y+x_{i 0}^{L_{i}} & \text { if lucky, enforcement } \\ 2 \cdot y & \text { if lucky, no enforcement } \\ y+x_{i 0}^{U_{i}} & \text { if unlucky, enforcement } \\ y & \text { if unlucky, no enforcement }\end{cases}
$$

and the first-order conditions of the maximization problem of debtor $i$ are:

$$
u^{\prime}\left(c_{i 0}\right)=u^{\prime}\left(c_{i 1} \mid \text { lucky, enforcement }\right)=u^{\prime}\left(c_{i 1} \mid \text { unlucky, enforcement }\right)
$$

Comparing Equations (3) and (4) with Equations (1) and (2), we find that consumption is no longer smooth across dates and states of nature. Debtors now face enforcement risk and are forced to consume their endowment in case of enforcement breakdown. As a result, Tomorrow's consumption becomes uncertain and borrowing declines.

This example shows how enforcement risk lowers the quality of existing assets and leads to suboptimal outcomes. Debtors would like to transfer wealth from states in which they are lucky

\footnotetext{
${ }^{10}$ Here we are using the assumption (in Footnote 2) that all asset payments involving debtors are enforced in Debtor's courts. In particular, this means that when there is an enforcement breakdown the international financial system does not make asset payments.
} 
to Today, but state-contingent bonds only allow them to transfer wealth from states in which they are lucky and there is no enforcement breakdown to Today. The weaker law enforcement is, the larger the distance between the asset that debtors need and the one that markets really offer, even though both assets might look the same on paper.

But this conclusion crucially relies on the unjustified assumption that secondary markets are missing. If those markets were available, debtors would use them to insure against the possibility of an enforcement breakdown. To see this, assume now that secondary markets open Tomorrow after endowments are known and before enforcement takes place. At this time, market participants know who is lucky and who is not. Given our assumptions about the international financial market, $i$-lucky ( $i$-unlucky) bonds will be traded in secondary markets at prices $1-\delta$ and $0(0$ and $1-\delta)$ depending on whether debtor $i$ is lucky or unlucky, respectively. At these actuarially fair prices, all debtors prefer to fully insure themselves so that they consume the same amount regardless of enforcement. They achieve this by using secondary markets to undo their net positions. Anticipating these trades, the budget set of debtor $i$ Today can be written as follows:

$$
c_{i 0}=0.5 \cdot\left(y-(1-\delta) \cdot\left(x_{i 0}^{L_{i}}+x_{i 0}^{U_{i}}\right)\right) \quad \text { and } \quad c_{i 1}= \begin{cases}2 \cdot y+(1-\delta) \cdot x_{i 0}^{L_{i}} & \text { if lucky } \\ y+(1-\delta) \cdot x_{i 0}^{U_{i}} & \text { if unlucky }\end{cases}
$$

and the first-order conditions of his maximization problem are now:

$$
u^{\prime}\left(c_{i 0}\right)=u^{\prime}\left(c_{i 1} \mid \text { lucky }\right)=u^{\prime}\left(c_{i 1} \mid \text { unlucky }\right)
$$

The effect of secondary markets can be seen by comparing the budget sets in Equations (3) and (5). Now debtors can issue bonds that de facto pay whenever they are lucky regardless of whether enforcement breaks down. Therefore, as long as the probability of enforcement is positive, debtors

choose the optimal consumption plan $c_{i 0}=c_{i 1}=y$ and support it by setting $x_{i 0}^{L_{i}}=-\frac{1}{1-\delta} \cdot y$ and $x_{i 0}^{U_{i}}=0$.

In this example, enforcement risk results from the possibility of complete enforcement breakdown. We turn next to a less extreme case in which there is always enforcement, but enforcement risk results from courts making mistakes when deciding which payments are to be enforced.

\subsection{Enforcement mistakes}

Assume now that courts make mistakes. In particular, there is a probability $\delta \in[0,0.5)$ that courts will declare a lucky debtor to be unlucky, and viceversa.

Once again, we start with the case in which secondary markets are missing. Given our assump- 
tions about the international financial market, the price of $i$-lucky and $i$-unlucky bonds must be both 0.5 since this is the probability that debtor $i$ is declared lucky or unlucky by the courts. ${ }^{11}$ Therefore, the budget set of debtor $i$ can be written now as follows:

$$
c_{i 0}=0.5 \cdot\left(y-x_{i 0}^{L_{i}}-x_{i 0}^{U_{i}}\right) \quad \text { and } \quad c_{i 1}= \begin{cases}2 \cdot y+x_{i 0}^{L_{i}} & \text { if lucky, declared lucky } \\ 2 \cdot y+x_{i 0}^{U_{i}} & \text { if lucky, declared unlucky } \\ y+x_{i 0}^{L_{i}} & \text { if unlucky, declared lucky } \\ y+x_{i 0}^{U_{i}} & \text { if unlucky, declared unlucky }\end{cases}
$$

The first-order conditions of the maximization problem of debtor $i$ are:

$$
\begin{aligned}
u^{\prime}\left(c_{i 0}\right) & =(1-\delta) \cdot u^{\prime}\left(c_{i 1} \mid \text { lucky, declared lucky }\right)+\delta \cdot u^{\prime}\left(c_{i 1} \mid \text { unlucky, declared lucky }\right) \\
& =\delta \cdot u^{\prime}\left(c_{i 1} \mid \text { lucky, declared unlucky }\right)+(1-\delta) \cdot u^{\prime}\left(c_{i 1} \mid \text { unlucky, declared unlucky }\right)
\end{aligned}
$$

Comparing Equations (7) and (8) with Equations (1) and (2), we find that consumption is no longer smooth across dates and states of nature. Debtors now face both endowment and enforcement risks, and it is not possible to insure against both of them by trading in primary markets alone. As a result, Tomorrow's consumption becomes uncertain and this might also affect debtors' desire to borrow. If $u^{\prime \prime \prime}(\cdot)>0$, weak law enforcement reduces debtors' borrowing. If $u^{\prime \prime \prime}(\cdot)<0$, the opposite occurs.

Once again, when secondary markets are missing enforcement risk lowers the quality of existing assets and leads to suboptimal outcomes. In this case, Debtors would like to transfer wealth from states in which they are lucky to Today, but state-contingent bonds only allow them to transfer wealth from states in which courts declare them to be lucky to Today.

When secondary markets exist, on the other hand, debtors can use them to insure against enforcement mistakes. Anticipating this, debtors then use primary markets for their original purpose, i.e. insuring against endowment risk and borrowing. To see this, assume that secondary markets open Tomorrow after endowments are known and before enforcement takes place. At this time, market participants know who is lucky and who is not. Given our assumptions about the international financial market, $i$-lucky ( $i$-unlucky) bonds will be traded in secondary markets at prices $1-\delta$ and $\delta(\delta$ and $1-\delta)$ depending on whether debtor $i$ is lucky or unlucky, respectively. ${ }^{12}$ At

\footnotetext{
${ }^{11}$ Here we are using again the assumption (in Footnote 2) that all asset payments involving debtors are enforced in Debtor's courts. In particular, this means that payments on bonds issued by the international financial market are also contingent on the rulings of Debtor's courts.

${ }^{12}$ Even if the international market did not participate in secondary markets, the prices would be the same. The reason is that debtors can diversify away the risk of any $i$-lucky bond and, as a result, this risk is not priced in equilibrium.
} 
these actuarially fair prices, all debtors prefer to undo their portfolios in order to insure themselves against enforcement mistakes. Taking these trades into account, the budget set of debtor $i$ Today becomes:

$$
c_{i 0}=0.5 \cdot\left(y-x_{i 0}^{L_{i}}-x_{i 0}^{U_{i}}\right) \quad \text { and } \quad c_{i 1}= \begin{cases}2 \cdot y+(1-\delta) \cdot x_{i 0}^{L_{i}}+\delta \cdot x_{i 0}^{U_{i}} & \text { if lucky } \\ y+\delta \cdot x_{i 0}^{L_{i}}+(1-\delta) \cdot x_{i 0}^{U_{i}} & \text { if unlucky }\end{cases}
$$

and the first-order conditions of his maximization problem are now:

$$
\begin{aligned}
u^{\prime}\left(c_{i 0}\right) & =(1-\delta) \cdot u^{\prime}\left(c_{i 1} \mid \text { lucky }\right)+\delta \cdot u^{\prime}\left(c_{i 1} \mid \text { unlucky }\right) \\
& =\delta \cdot u^{\prime}\left(c_{i 1} \mid \text { lucky }\right)+(1-\delta) \cdot u^{\prime}\left(c_{i 1} \mid \text { unlucky }\right)
\end{aligned}
$$

The effect of secondary markets can be seen by comparing the budget sets in Equations (7) and (9). Now there exist combinations of bonds that deliver income in those states in which a debtor is lucky or unlucky, regardless of what the courts declare. Secondary markets change the span of existing assets in such a way that the budget set is unaffected by enforcement problems. Therefore, debtors choose the optimal consumption plan, i.e. $c_{i 0}=c_{i 1}=y$. The only effect of enforcement mistakes is that debtors support this consumption plan with a different combination of assets, i.e. $x_{i 0}^{L_{i}}=-\frac{1-\delta}{1-2 \cdot \delta} \cdot y$ and $x_{i 0}^{U_{i}}=\frac{\delta}{1-2 \cdot \delta} \cdot y$.

\subsection{Discussion}

These two examples illustrate how secondary markets help solve problems derived from the government's inability to enforce. The role of secondary markets is quite different from that of primary markets though. While the latter allow borrowing and provide insurance against endowment risk, the former provide insurance against enforcement risk.

How robust is this result? Our setup captures just one aspect of these problems; namely, weak law enforcement may generate random redistributions. However, the result is likely to apply also in other situations. For example, consider the case in which enforcement entails high resource costs. In this case, secondary markets enable individuals to undo their portfolios to save on enforcement costs. It might seem also that secondary markets are not helpful if the apparatus of state law is absent. But even then, secondary markets might help by leveraging private enforcement mechanisms.

Moreover, the roles of secondary markets in dealing with problems derived from governments' unwillingness and inability to enforce are compatible with each other and can be performed simultaneously. To see this, assume now that in the world of the previous section Debtor's government cannot commit Today to enforcing payments Tomorrow. This brings back the problem of sovereign 
risk. To eliminate this risk, the distribution of bond holdings that comes out of the secondary market must be such that the government prefers to enforce payments. But, since debtors have incentives to insure themselves against enforcement mistakes, they undo their portfolios in secondary markets. As a result, the average utility of debtors is unaffected by the government's enforcement decision and, thus, enforcing payments is consistent with government optimization.

\section{What are enforcement problems?}

This paper began with the assertion, which few economists would dispute, that markets cannot work well without an adequate institutional framework that ensures that asset payments are enforced. The results reported here, however, suggest an important twist to this argument. Weak enforcement institutions interfere with the workings of primary markets only if secondary markets are missing or do not function properly. Otherwise, assets issued in primary markets are retraded so as to eliminate the efficiency losses brought about by enforcement problems.

Since empirical evidence suggests that weak enforcement institutions do matter for economic performance, it is important to understand when and why secondary markets cannot perform this useful role. One possibility is that there exist additional frictions, unrelated to enforcement problems, that prevent secondary markets from working well. In our previous paper, we identified three such frictions: transaction costs, the presence of large agents, and the ability of governments to commit to enforcing or not enforcing certain payments. ${ }^{13}$ A second possibility is that what we call enforcement problems are nothing but symptoms of other, deeper, frictions that simultaneously weaken enforcement institutions and impair the workings of secondary markets. A natural candidate friction of this type is asymmeric information. ${ }^{14}$ Further progress on the effects of weak enforcement institutions on economic outcomes will hinge on our collective ability to theoretically and empirically explain why secondary markets often fail to solve enforcement problems in the real world.

\footnotetext{
${ }^{13}$ In particular, we showed how these frictions limit the effectiveness of secondary markets in solving the problem of unwillingness to enforce. For lack of space, we do not repeat the analysis for the problem of inability to enforce, even though many of the arguments developed in our earlier paper would also apply. Broner and Ventura (2005 and 2007) discuss at length the case in which governments can preempt secondary markets by committing to not enforcing certain payments before individuals retrade existing contracts.

${ }^{14} \mathrm{~A}$ simple example makes the point. Consider the world of Subsection 3.2 with one slight variation: Tomorrow, there is asymmetric information as to who has been lucky or unlucky, and it is up to the courts to verify it. As before, $\delta$ is the probability that courts make a mistake when verifying the status of an individual debtor. At first glance, nothing has changed. All we have done is to justify enforcement mistakes as the consequence of another friction, namely, asymmetric information. And yet this has crucial consequences because asymmetric information affects the workings of secondary markets. Since the international financial market does not know who is lucky or unlucky, it must offer the same prices to both types of individuals. This gives rise to adverse selection in secondary markets, making it too expensive for unlucky debtors to fully undo their portfolios and exposing them to enforcement risk in equilibrium. In this case, secondary markets would still be used and this would raise welfare. But it is no longer possible to attain the optimal consumption plan. The presence of asymmetric information that gives rise to default risk also prevents secondary markets from eliminating it.
} 


\section{References}

[1] Broner, F., A. Martin and J. Ventura, (2006). "Sovereign Risk and Secondary Markets," mimeo, CREI and Universitat Pompeu Fabra.

[2] Broner, F., and J. Ventura, (2005). "Globalization and Risk Sharing," mimeo, CREI and Universitat Pompeu Fabra.

[3] Broner, F., and J. Ventura, (2007). "Rethinking the Effects of Financial Liberalization," mimeo, CREI and Universitat Pompeu Fabra.

[4] Dixit, A. (2004). Lawlessness and Economics: Alternative Modes of Governance. Princeton University Press.

[5] Dixit, A. (forthcoming). "Economic Governance," in S. Durlauf and L. Blume (eds.) The New Palgrave Dictionary in Economics, $2^{\text {nd }}$ edition, London: Palgrave MacMillan. 